\title{
Interpretation on the Profound Female Consciousness in Shen Congwen's Xiao Xiao
}

\author{
Honghua Shi \\ Liaoning University of International Business and Economics, Dalian Liaoning, 116000, China
}

Keywords: Xiao Xiao, Shen Congwen, Female consciousness, Tragic destiny, Suspended, Growth.

\begin{abstract}
Xiao Xiao is the short story masterpiece of Chinese modern writer Shen Congwen. It not only describes the bright side of the pastoral scenery far away from the hustle and bustle, but also profoundly reveals the dark side of the folk custom in western Hunan and women' s hardship, more depicts a stubborn, persevering, sincere, kind woman with miserable fate, named as Xiao Xiao. Someone comments that Xiao Xiao's growth experience is suspended and delayed, she reflects the author's irreconcilable ambivalence between his treatment on female consciousness in western Hunan and the modern civilization. This paper studies Xiao Xiao' s gradually formed female consciousness in 4 growing periods from text of the work and profoundly analyzes her tragedy under the human beauty.
\end{abstract}

\section{Introduction}

1920s 1930s is the most turbulent era in China, Shen Congwen created Xiao Xiao during this period. This is an unworldly work, without social unrest and the intrusion of war, Xiao Xiao is just a country girl far from the madding crowd in western Hunan, but her growth experience is sad and painful. Xiao Xiao reveals female's life and survival state in western Hunan at that time with her growth experience of a child bride, most of them go through hardships and with miserable fates. According to Shen Congwen' s words "Their souls are rough, but their sexual desires are pure and the sweets and bitters of life formed by all the productive relations."

\section{View on Xiao Xiao's female consciousness formation and change from text form}

View from the text form, Xiao Xiao' s growth experience shall be divided into four periods. During these four periods, Xiao Xiao grows up slowly and experiences the constant evolution and struggle of female consciousness, gradually grows into a little woman from a sucking child.

The first period.

The first period should be that Xiao Xiao becomes a child bride, at the beginning, she is still a innocent girl, while her husband is just a 3 years old, weanling little boy. During this period, though Xiao Xiao has already become a wife, she is still just a child, her female consciousness has not formed yet, she will only hold "little brother" to play under the willow in front of the village, to pick up escargots on the riverside. For a girl of 12 years old, she is at the age of loving dream and play, all the funny things can make this girl laugh heartly, she is easily to be satisfied, therefore, she has no real female consciousness at this period.

\section{The second period.}

During the second period, Xiao Xiao has already come to the age of 15 years old, at this time, her female consciousness has already begun to emerge, during the formation process of her female consciousness, her life changes little, still does manual work, takes care of her little husband, cooks, and being tortured by her mother-in-law. In the novel, Xiao Xiao is described as the unknown ricinus communis in the corner of the garden who lives in the wind and the rain, though not be concerned, she also grows gradually, physically and psychologically. As she grows up day after day, Xiao Xiao begins to have the need of love, while in this novel, what dominants Xiao Xiao' s love hormone is not the free air, but the folk custom in the villages of western Hunan that singing for love. At this time, the 23 years old longterm hired hand--Hua Gou, with his sonorous folk songs and fine-sounding, makes 
Xiao Xiao cannot control her passion and produce hazy feeling of love, with the intensifying of female consciousness and the physiological mature, Xiao Xiao finally puts into Hua Hou's arms, one day, Hua Hua obeyed Hua Gou, at that she grew up overnight and became a little woman. As it were, Hua Gou becomes the guide for Xiao Xiao's female consciousness, he opens Xiao Xiao' s sexual desire step by step, takes Xiao Xiao away from her stable life obit.

\section{The third period.}

Xiao Xiao has accidental pregnancy at the age of 16 years old, with belly becomes bigger and bigger, Xiao Xiao asks Hua Gou for help, while the cowardice Hua Gou has no sense of responsibility, he chooses to give up and escape from Xiao Xiao, leaves without saying goodbye. The helpless Xiao Xiao can only hide this secret in the bottom of her heart, not dare to make public, her mind is full of guilt and regret. But no matter how troubled Xiao Xiao is, changes in her body and baby in her belly still grows firmly, the baby does not come to a premature end for Xiao Xiao' s swallowing incense ashes and drinking cold water. Day after day, Xiao Xiao more and more falls into the physiological and psychological tortures. At this time, Xiao Xiao' s consciousness is in disorder and unease, she scares to face her families, especially her mother-in-law, but finally her pregnancy is found by her mother-in-law, this take sa sudden turn on Xiao Xiao' s fate and becomes worse rapidly, directly being "sunk into the deep pool”. Though Xiao Xiao has committed unforgivable mistake, her uncle is kind, he does not willing to sink the pregnant Xiao Xiao into the pool, thus he leaves her for appropriate people to take her away. Fortunately, there is no right people to take her away until the birth of her child--Niu Er. Xiao Xiao is saved in this way, during this period, Xiao Xiao lives in panic, her heart is with huge contradiction, she is more scared t speak than before, until the child is born, new mother --Xiao Xiao begins feel that her world is suddenly enlightened, her son seems explored a new path for her, but she does not know that she goes for another destiny quietly.

\section{The fourth period.}

After entering the fourth period, Xiao Xiao has become a 20 years old adult woman. When she is 26 years old, Xiao Xiao officially marries her husband, at this time, Niu Er is already 10 years old. When she is 28 years old, Xiao Xiao, as a mother and a wife, gives birth to her second child for her husband and another "Xiao Xiao" joins in her family, she has a third identity--mother-in-law. Xiao Xiao' s identity change represents the disillusion of her girlhood dream, also represents the full maturity of her female consciousness, but as a country woman close to 30 years ols, Xiao Xiao' s noema and female consciousness are still uncultured, dumb and even stubborn.

From the ideographic connotation of Shen Congwen's novel, the growth he describes and focuses on is not the growth of ordinary persons, but the difficult growth like Xiao Xiao, it also contains main metaphors in connotation plot like innocence, ignorant, maturity. So to say, Xiao Xiao' s female growth is suspended and delayed, because her two incidents changed her life--short contact with Hua Gou and the birth of her son. These two turning points are also the key points for the formation of her female consciousness. During these two periods, Xiao Xiao' s spiritual world is always in the desolate and passive state, from beginning to end, she does not control her own female consciousness and destiny. Therefore, Xiao Xiao' s growth experience has always been suspended, she never experiences the growth of humanity consciousness ${ }^{[1]}$.

\section{Xiao Xiao’ s tragic female consciousness under humanity beauty}

We say Xiao Xiao did not really experience the growth of humanity consciousness does not represent she has no female consciousness. During the era that feudal ethical and moral concept dominants the society, Shen Congwen's description on characters is comprehensive, he tries to reveal and tell people that under the influence of the feudal ethical society, the female characters in the literature works also try to get rid of the double chains of morality and fate, though this kind of struggle might be meaningless, the ideological restraints of feudal females must be highlighted.

\section{Xiao Xiao's unconsciousness on her own tragedy.}

Xiao Xiao' s heart is completely restraint, from being a child bride to accidental pregnancy to the birth of her son and becomes a mother-in-law at last. Xiao Xiao' s largest spiritual restraint is that she 
never realized her life tragedy, that is her unconsciousness on her own tragedy.

First of all, Xiao Xiao has no consciousness on her identity changes, because she does not know her parents at all, she has no memory about her parents, because she was fostered by her uncle since childhood. After being married, she also has no concepts on her marriage, she just knows that she needs to try to protect and take care of her little husband, at this time, instead of saying she is a baby-sitter rather than a wife. Therefore, we can say that during the first period, Xiao Xiao has no consciousness on her identity and future life, this also lays her life tragedy.

Secondly, Xiao Xiao also has not completely awaken from her own female consciousness. Though with the growing of her age, Xiao Xiao also begins to realize all kinds of differences between males and herself, as grandpa said "Xiao Xiao, you have already grown up, you will be a girl student in the future.” But for Xiao Xiao, this sentence is meaningless, because she has no concepts on her female role, let alone females' self-protection and rights consciousness. From Xiao Xiao' s characters in the novel, in her consciousness, girl student is a distant and fearful concept, thus she says when caring her litter husband that "You have to obey, or girl students will come out to bite you". Obviously, Xiao Xiao doesn't know how to maintain her female rights, her female consciousness is weak and indistinct. But after the short love with Hua Gou, Xiao Xiao grows like an adult both physiologically and psychologically. Objectively, Hua Gou awakes Xiao Xiao' s female consciousness. Hua Gou' s considering on Xiao Xiao is pointed, thus he collects songs about girl students to sing for Xiao Xiao. Under Hua Gou' s “cultivation”, Xiao Xiao' s female consciousness is gradually formed and mature, thus she will generate the so called favorable expression. But this is a violation of ethics under the temporal constraints, Xiao Xiao’ s female consciousness is gradually awaken.

Twice awaken of female consciousness in Xiao Xiao' $s$ life.

In Xiao Xiao' s life, the female consciousness has been awaken for twice, one is the "girl students" concept from grandpa, another one is from Hua Gou on the materialistic level. The first time awakes the mental level of Xiao Xiao' s female consciousness, this makes Xiao Xiao has a primary understanding on the concept of "girl student', this is her first contact with the outer world. While the second awaken is on the material level, this awaken is complete and thorough, Xiao Xiao not only understands the girl students in her heart, but also generates fantasy for males, this is unable to resist for a girl did not contact with the world, thus we can see that Hua Gou spent some energy on Xiao Xiao. He starts with the concept of "girl student” that is ignorant for Xiao xiao to open her female consciousness world. At the time surrounded with feudal ethics, Xiao Xiao is hard to get rid of this kind of tragedy, thus for Xiao Xiao, unconsciousness lets her obey her family to be a child bride, while consciousness awaken makes her fall into sexual desire and to be criticized by the society, this also increases her life tragedy.

\section{Backward and ignorance of Xiao Xiao' s female consciousness.}

From Xiao Xiao herself, we can see that her mental consciousness is completely backward, this is also one of the root causes of her tragedy. Firstly, Xiao Xiao lives in the country where mental and material are relatively poor, the feudal ethical concepts control his thinking and behaviors, thus Xiao Xiao inevitably falls into spiritual dilemma and becomes a child bride. At this time, Xiao Xiao's spiritual consciousness is completely dark and helpless, thus to say she is unconscious, has no own thoughts, backward and ignorant. Xiao Xiao has no idea on females'bright and freedom, let alone female rights. Further, Xiao Xiao cannot to get out from the spiritual consciousness ignorance, she also doesn't want to get out, because of the oppression of feudalism, while the image of the spiritual oppression performer is too huge, this makes Xiao Xiao be absolutely obedient and finally become a wheal gear in the feudalism spirit ethical oppression even push its progress.

In the novel, Xiao Xiao once tried to get relief of spiritual consciousness through worshiping the God, but actually Xiao Xiao cannot get out of the constraints of her heart, as time passes, she completely losses her courage and thoughts to fight with the feudal society, at last Xiao Xiao believes that even God cannot help me, what can I do? Xiao Xiao was described as a people always does same thing without caring about her own safety. But Xiao Xiao's weak resistance also let her powerless, after her pregnancy was revealed, she chose to make no resistance. For the female completely restricted by inner spiritual consciousness, the spiritual cage is heavy and cannot climbed over, in her 
consciousness, standing still might be the best result ${ }^{[2]}$.

\section{Patriarchal bondage in Xiao Xiao's female consciousness.}

Xiao Xiao' s female consciousness comes from male and is restricted by male, therefore, Xiao Xiao' s female consciousness restraints and tragic fate cannot just be ascribed to the society. In that era, females had no speaking right, not alone freedom, females were regarded as accessory and equivalent of interest division in the male society. Under this trend, Xiao Xiao' $\mathrm{s}$ female consciousness was restricted and played by uncle and Hua Gou, she did not get freedom and consciousness in her whole life. At the end of this novel, Xiao Xiao chooses a girl older than her son as child bride, she follows practice of the older and continues the tradition, this indicates that in her consciousness, she accepts her fate, her heart is depressive and poor, she is no longer for freedom, but becomes the performer of patriarchal bondage, continue to direct the tragedy ${ }^{[3]}$.

\section{Conclusion}

Xiao Xiao shows the female tragedy, the awaken and corruption of female consciousness in western Hunan society. Woman like Xiao Xiao, her whole life is indulged in the mire of spirit and fate, her lives in pain and struggle for her whole life, thus they cannot get out from their spiritual ignorance, they also have no complete female consciousness as modern females, because "Xiao Xiaos" have no more rational spirit, thinking weapons and moral courage to stick to their own principle and bottom line, this is the tragedy of the society but more of a tragedy of human being.

\section{References}

[1] Liang Xiaojuan. The Suspended Female Growth--Reread Xiao Xiao, Journal of Hubei Institute of Adult Education, 2011,17(1):77-78.

[2] Li Li. Interpretation on the Female Tragic Fate in Shen Congwen's Xiao Xiao, Short Stories, 2014,5(9):37-38.

[3] Fan PeiQian. Discussion on Shen Congwen's Female View, Qufu Normal University, 2007.21-23. 